\title{
Local Cu Component Engineering to Achieve Continuous Carrier Transport for Enhanced Kesterite Solar Cells
}

Yuechao Zhao ${ }^{\dagger a}$, Xiangyun Zhao ${ }^{\dagger b}$, Dongxing Kou ${ }^{\mathrm{a} *}$, Wenhui Zhou ${ }^{\mathrm{a}}$, Zhengji Zhou ${ }^{\mathrm{a}}$, Shengjie Yuan ${ }^{\mathrm{a}}$, Yafang Qi ${ }^{\mathrm{a}}$, Zhi Zheng ${ }^{\mathrm{c}}$ and Sixin $\mathrm{Wu}^{\mathrm{a} *}$

${ }^{a}$ Key Lab for Special Functional Materials, Ministry of Education, National \& Local Joint Engineering Research Center for High-Efficiency Display and Lighting Technology, School of Materials Science and Engineering, Collaborative Innovation Center of Nano Functional Materials and Applications, Henan University, Kaifeng 475004, China.

${ }^{\mathrm{b}}$ School of Metallurgy and Environment, Central South University, Changsha 410083, China 'Inst Surface Micro \& Nano Mat, Key Lab Micronano Energy Storage \& Convers Mat He, Xuchang University, Xuchang, Henan 461000, China.

E-mail:koudongxing@henu.edu.cn; wusixin@henu.edu.cn. 


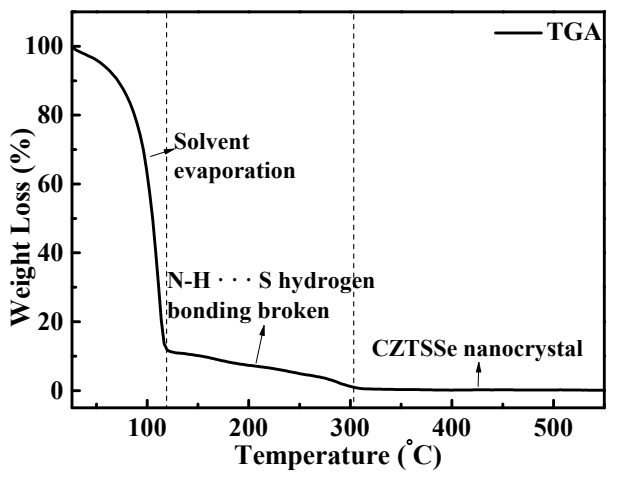

Figure S1. TGA curve of CZTSSe precursor solution.
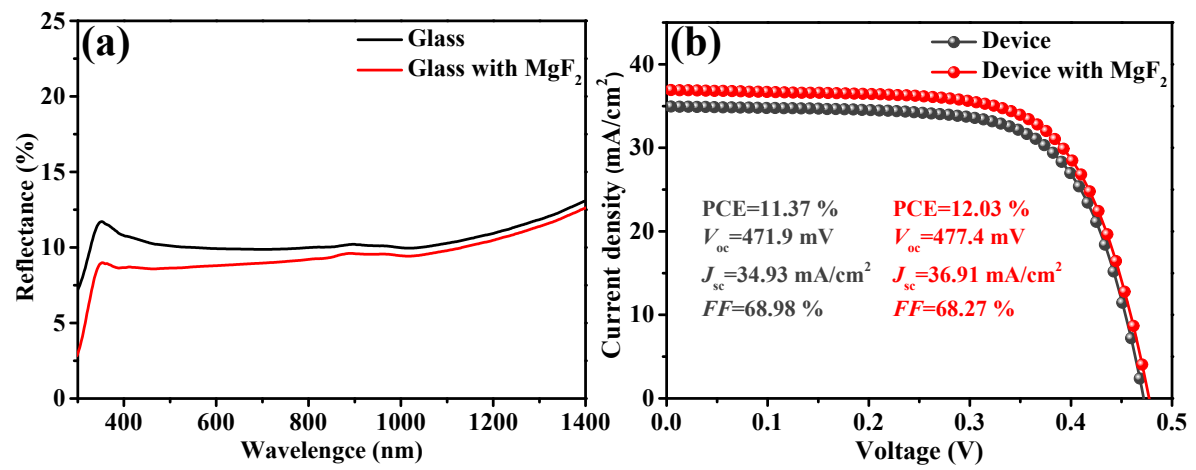

Figure S2 (a) The reflectance spectra of ITO glass and (b) overall efficiency of CZTSSe device before and after the evaporation of $\mathrm{MgF}_{2}$.

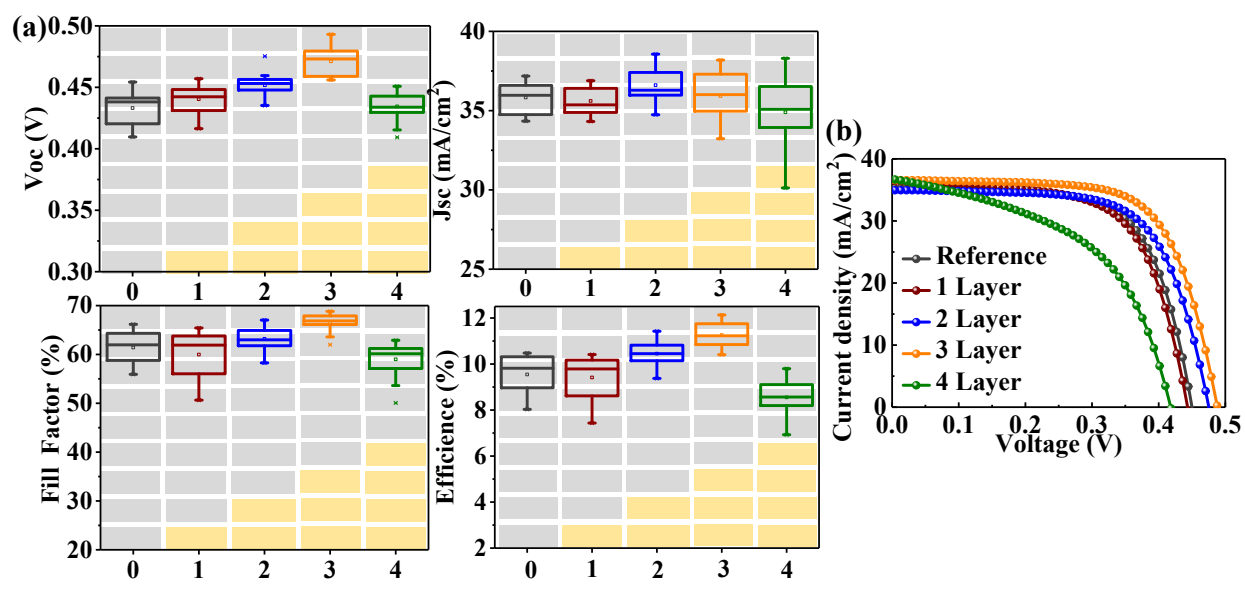

Figure S3. (a) Statistical box diagram of photovoltaic parameters and (b) $J-V$ curves for CZTSSe solar cells with different bottom higher $\mathrm{Cu}$ content layers. The total layer of bottom $\mathrm{Cu}$-higher precursor films is nine and the $\mathrm{Cu} /(\mathrm{Zn}+\mathrm{Sn})$ ratio of top layers and bottom layers is 0.72 and 1.1 , respectively. 

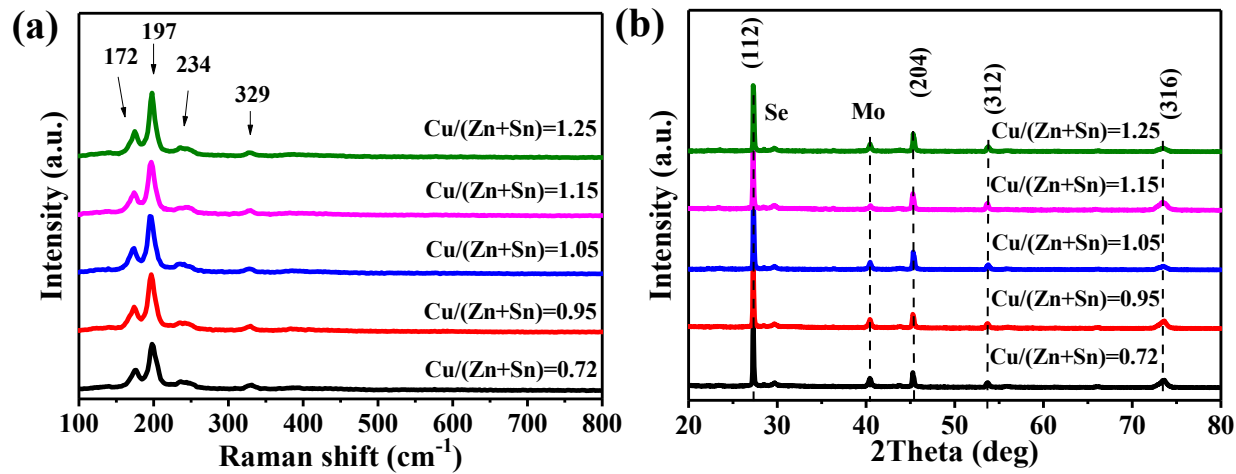

Figure S4. (a) Raman spectra and (b) X-ray diffraction (XRD) patterns of selenized CZTSSe

films with different $\mathrm{Cu}$ gradient profile.
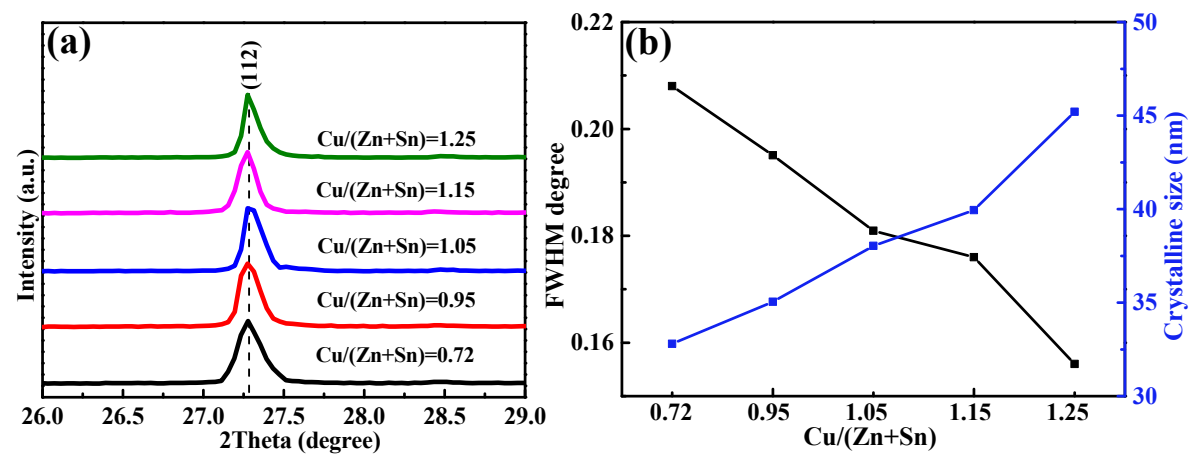

Figure S5. (a) Enlarged XRD peak of (112) plane and (b) FWHM (112) and average crystalline size of the selenized CZTSSe films with different $\mathrm{Cu}$ gradient.

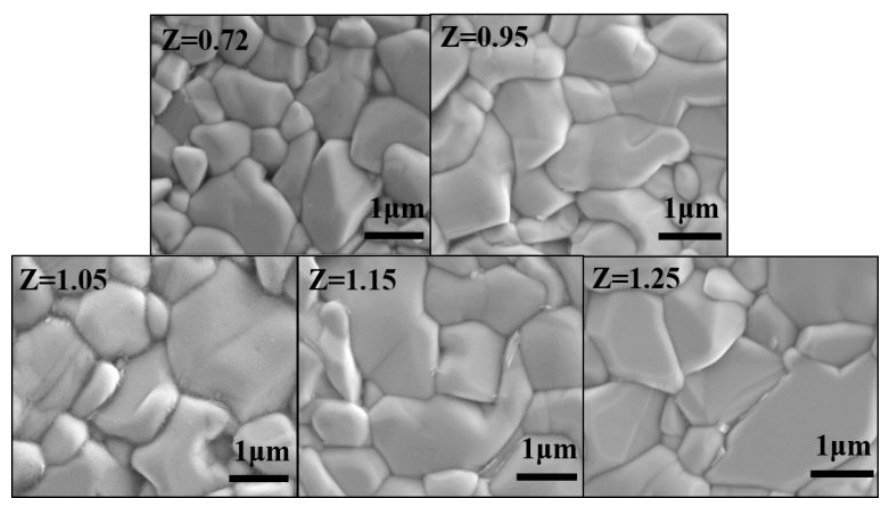

Figure S6. The top-view SEM images for bottom $\mathrm{Cu}$-higher CZTSSe films with different $\mathrm{Cu} /(\mathrm{Zn}+\mathrm{Sn})$ ratio in the bottom precursor absorber. 

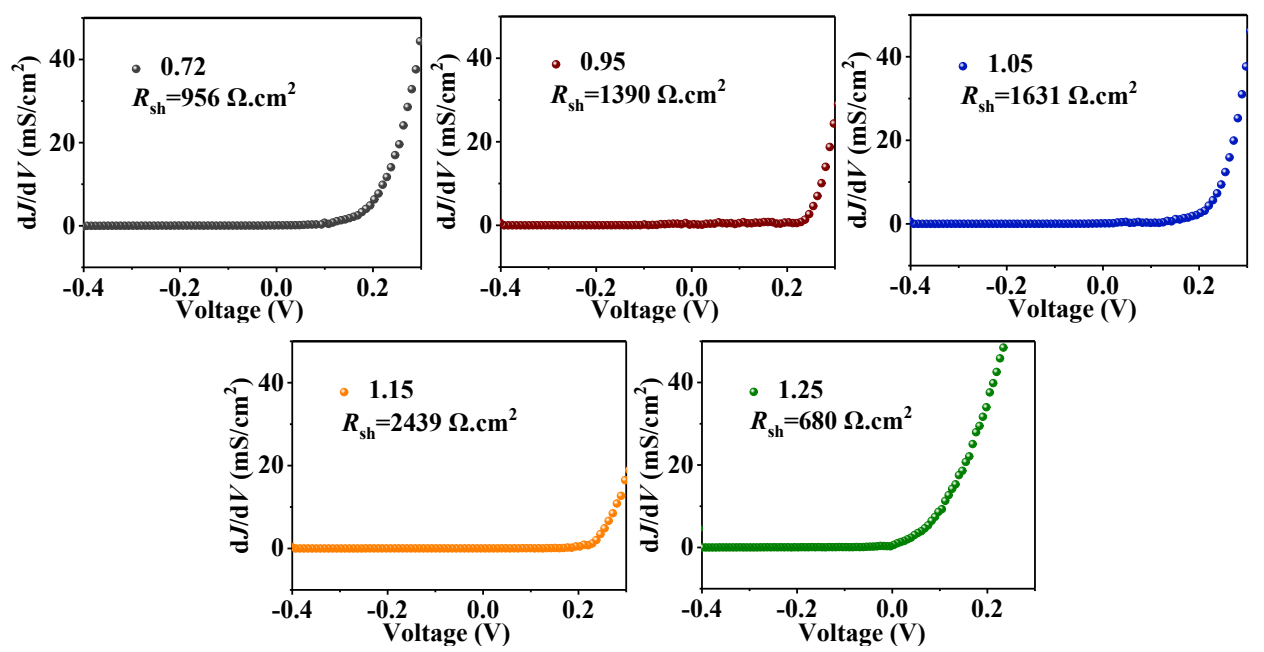

Figure S7. $d J / d V$ vs. $V$ curves, where the shunt resistance of CZTSSe devices with different

$\mathrm{Cu}$ gradient profile is the reciprocal of shunt conductance $\left(G_{\mathrm{sh}}\right)$ evaluated from the plateau value ranging from $-0.3-0 \mathrm{~V}$.
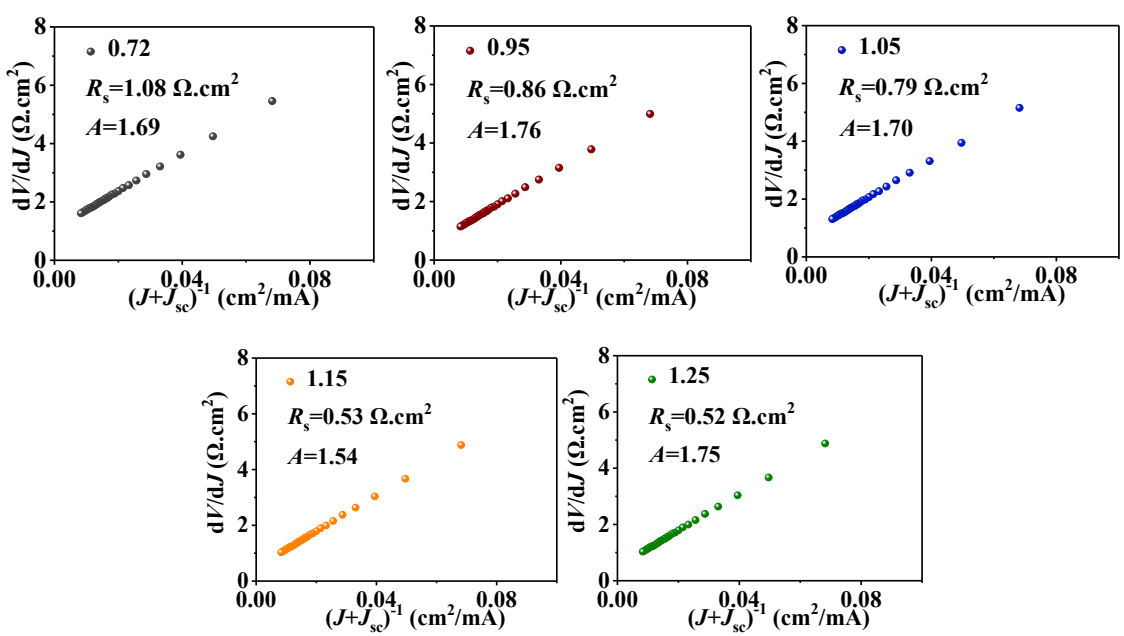

Figure S8. $d V / d J$ vs. $\left(J+J_{\mathrm{sc}}\right)^{-1}$ plots, where the series resistance $\left(R_{\mathrm{s}}\right)$ of CZTSSe devices with different $\mathrm{Cu}$ gradient profile is extracted from the y-intercept. 

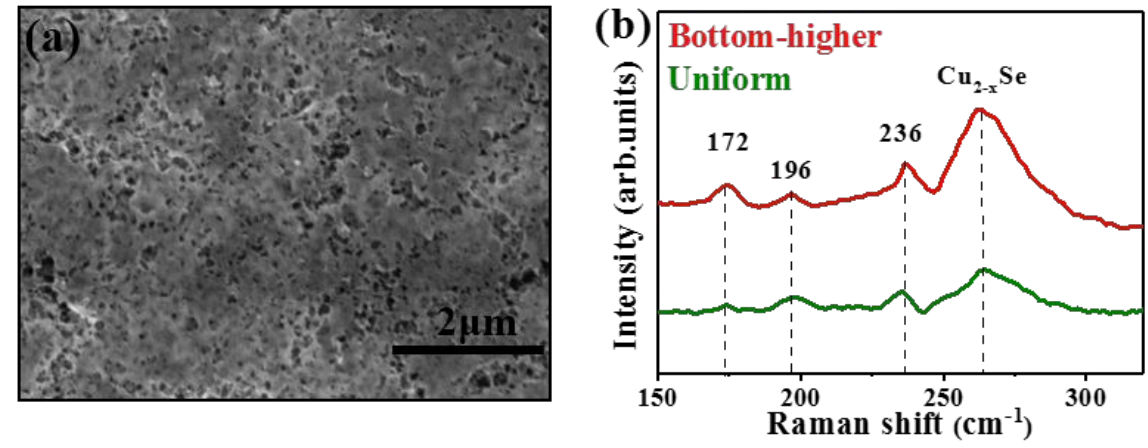

Figure S9. (a) The surface morphology of the fine grain layer after etching the large grain on top. (b) Raman spectrum of the etched fine grain layers for uniform and bottom Cu-higher CZTSSe absorbers.
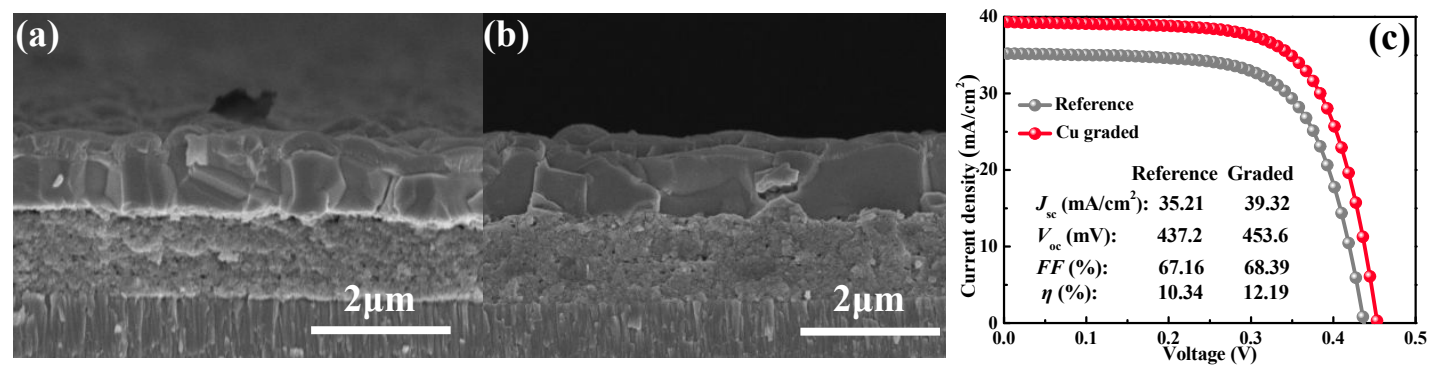

Figure S10. Cross-section SEM images of (a) uniform Cu-poor and (b) Cu-graded CZTSSe solar cells with bilayer absorber structure. (c) $J-V$ curves of bilayer structured $\mathrm{Cu}$-poor and $\mathrm{Cu}$-graded CZTSSe solar cells. The $\mathrm{Cu}$-graded precursor films consists of six $\mathrm{Cu}$-poor layers $(\mathrm{Cu} /(\mathrm{Zn}+\mathrm{Sn})=0.72)$ on top and three $\mathrm{Cu}$-higher layers in the bottom $(\mathrm{Cu} /(\mathrm{Zn}+\mathrm{Sn})=1.15)$.
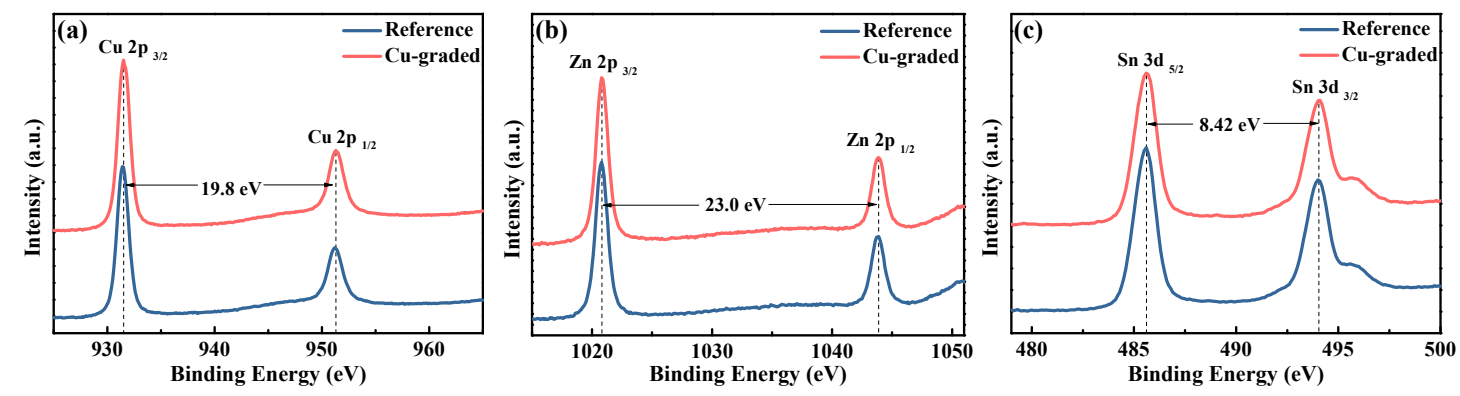

Figure S11. XPS peak of (a) $\mathrm{Cu} 2 p$, (b) $\mathrm{Zn} 2 p$, and (c) $\mathrm{Sn} 3 d$ obtained from reference and Cu-graded CZTSSe films. 


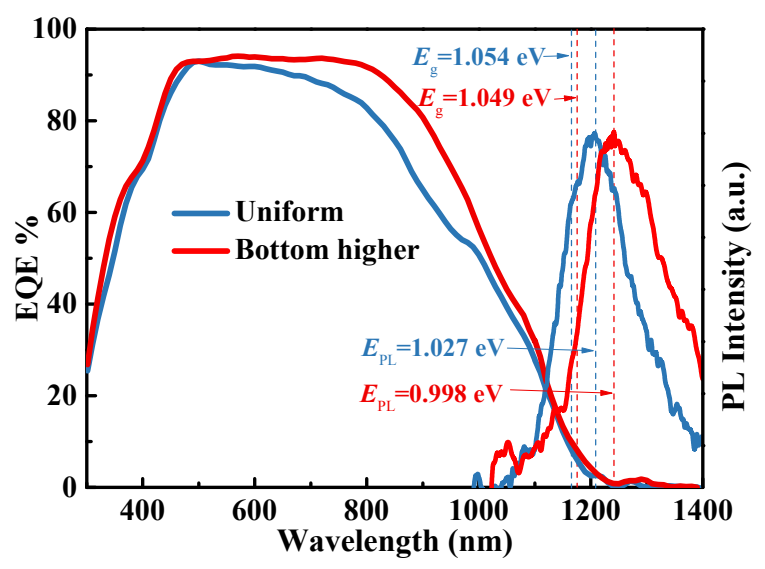

Figure S12. Extracted bandgap from both EQE and PL spectra of the uniform Cu-poor (reference) and bottom $\mathrm{Cu}$-higher $(\mathrm{Cu} /(\mathrm{Zn}+\mathrm{Sn})=1.15)$ samples.
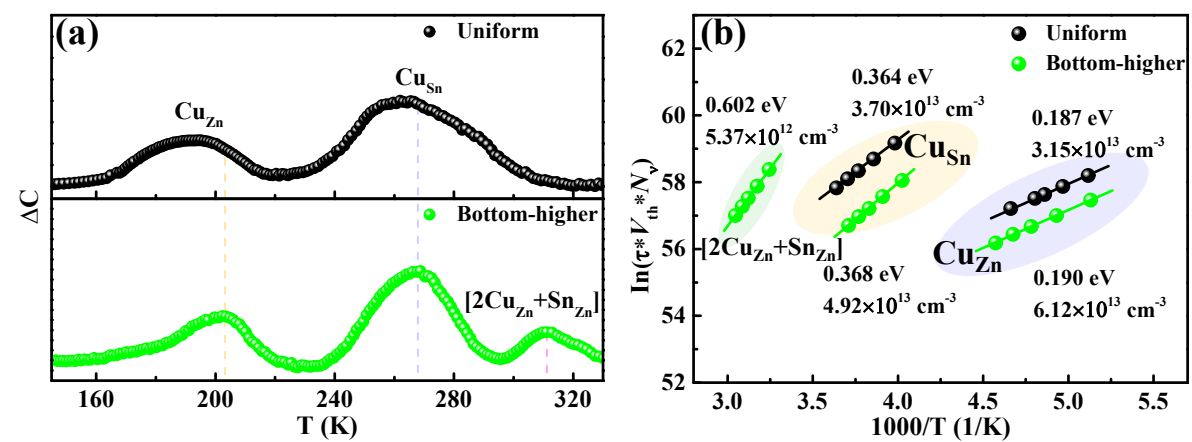

Figure S13. (a) The C-DLTS Arrhenius curves of uniform Cu-poor and bottom Cu-higher CZTSSe solar cells. (b) The derived $E_{\mathrm{a}}$ and $\mathrm{N}_{\mathrm{T}}$ of $\mathrm{Cu}_{\mathrm{Zn}}, \mathrm{Cu}_{\mathrm{Sn}}$ defects and $\left[2 \mathrm{Cu}_{\mathrm{Zn}}+\mathrm{Sn}_{\mathrm{Zn}}\right]$ defect clusters for uniform $\mathrm{Cu}$-poor and bottom $\mathrm{Cu}$-higher CZTSSe solar cells.

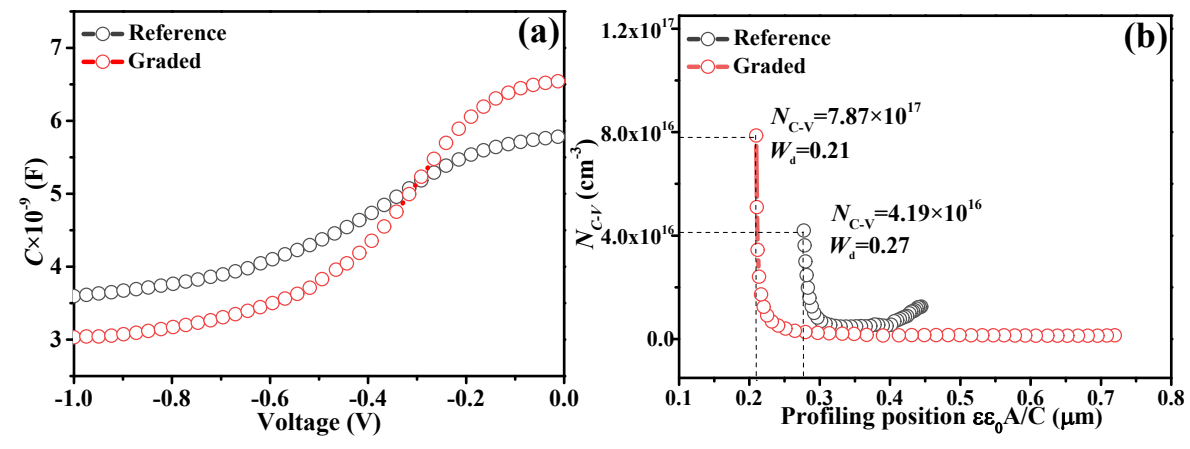

Figure S14. (a) $C-V$ curves and (b) derived space-charge density $N_{\text {c-v }}$ for Cu-poor and $\mathrm{Cu}$-graded devices. These data were performed under 0 to $-1 \mathrm{~V}$ at $300 \mathrm{~K}$. 
The quantified depletion region width could be straightforward derived from the free carrier density as a function of profiling position $\left(\varepsilon_{0} \varepsilon A / C\right)$ at $\mathrm{X}$-axis of zero bias. $N_{\mathrm{c}-\mathrm{v}}$ can be obtained according to the given equation,

$$
N_{C-V}=\frac{C^{3}}{q A^{2} \varepsilon_{0} \varepsilon_{S}}\left(\frac{d C}{d V}\right)^{-1}
$$

wherein the $C, A, \varepsilon_{\mathrm{s}}, \varepsilon_{0}$ and $q$ are all constants.

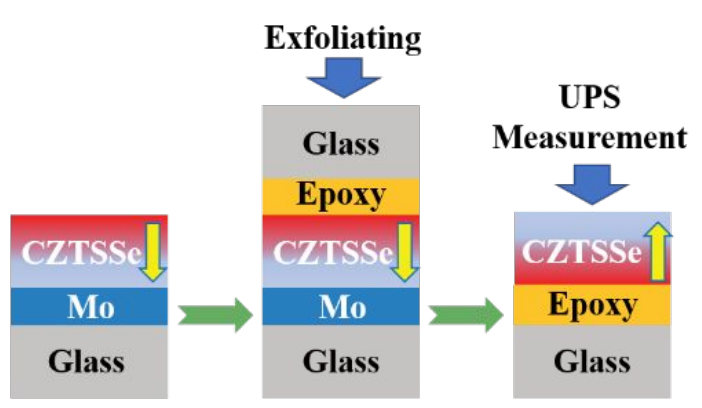

Figure S15. Schematic diagrams of UPS measurement on the surface of exfoliated bottom absorber. 
Table S1. The detailed photovoltaic parameters of CZTSSe solar cells with different bottom higher $\mathrm{Cu}$ content layers.

\begin{tabular}{ccccc}
\hline $\begin{array}{c}\text { Layer numbers } \\
\mathrm{Cu} /(\mathrm{Zn}+\mathrm{Sn})=1.1\end{array}$ & $\begin{array}{c}V_{\mathrm{oc}} \\
(\mathrm{mV})\end{array}$ & $\begin{array}{c}J_{\mathrm{sc}} \\
\left(\mathrm{mA} / \mathrm{cm}^{2}\right)\end{array}$ & $\begin{array}{c}F F \\
(\%)\end{array}$ & $\begin{array}{c}\eta \\
(\%)\end{array}$ \\
\hline 0 & 451.9 & 35.07 & 66.02 & 10.46 \\
1 & 443.5 & 36.46 & 64.23 & 10.38 \\
2 & 475.3 & 34.94 & 67.03 & 11.13 \\
3 & 488.2 & 36.58 & 67.94 & 12.13 \\
4 & 406.6 & 36.06 & 62.22 & 9.12 \\
\hline
\end{tabular}

Table S2. The detailed photovoltaic parameters of champion $\mathrm{Cu}$ gradient and IBM record CZTSSe solar cells.

\begin{tabular}{ccccccc}
\hline Cell & $\begin{array}{c}\eta \\
(\%)\end{array}$ & $\begin{array}{c}V_{\text {oc }} \\
(\mathrm{mV})\end{array}$ & $\begin{array}{c}J_{\mathrm{sc}} \\
\left(\mathrm{mA} \mathrm{cm}^{-2}\right)\end{array}$ & $\begin{array}{c}F F \\
(\%)\end{array}$ & $\begin{array}{c}\text { Band gap } \\
(\mathrm{eV})\end{array}$ & $\begin{array}{c}\mathrm{S} /(\mathrm{S}+\mathrm{Se}) \\
(\%)\end{array}$ \\
\hline This work & 12.54 & 480.3 & 37.87 & 69.0 & 1.05 & 17 \\
IBM & 12.6 & 513.4 & 35.21 & 69.8 & 1.13 & 23 \\
\hline
\end{tabular}

Table S3. EDS data for the component percent of $\mathrm{Cu}, \mathrm{Zn}, \mathrm{Sn}, \mathrm{S}$, Se within each layer of uniform $\mathrm{Cu}$-poor and bottom $\mathrm{Cu}$-higher tri-layered absorber illustrated in Figure $3 \mathrm{~d}$.

\begin{tabular}{cccccc}
\hline \multicolumn{4}{c}{ Uniform Element Atomic \% Cu-gradedElementAtomic\% } \\
\hline \multirow{4}{*}{1} & $\mathrm{~S}$ & 11.2 & & $\mathrm{~S}$ & 11.19 \\
& $\mathrm{Sn}$ & 9.09 & & $\mathrm{Sn}$ & 9.2 \\
& $\mathrm{Cu}$ & 15.77 & 4 & $\mathrm{Cu}$ & 16.45 \\
& $\mathrm{Zn}$ & 11.2 & & $\mathrm{Zn}$ & 10.15 \\
& $\mathrm{Se}$ & 52.74 & & $\mathrm{Se}$ & 50.69 \\
\hline \multirow{4}{*}{2} & $\mathrm{~S}$ & 16.22 & & $\mathrm{~S}$ & 13.79 \\
& $\mathrm{Sn}$ & 4.05 & & $\mathrm{Sn}$ & 4.41 \\
& $\mathrm{Cu}$ & 3.51 & 5 & $\mathrm{Cu}$ & 5.48 \\
& $\mathrm{Zn}$ & 3.74 & & $\mathrm{Zn}$ & 3.66 \\
& $\mathrm{Se}$ & 72.48 & & $\mathrm{Se}$ & 72.66 \\
\hline & $\mathrm{S}$ & 12.3 & & $\mathrm{~S}$ & 12.51 \\
& $\mathrm{Sn}$ & 8.28 & & $\mathrm{Sn}$ & 8.31 \\
3 & $\mathrm{Cu}$ & 13.63 & 6 & $\mathrm{Cu}$ & 16.24 \\
& $\mathrm{Zn}$ & 10.38 & & $\mathrm{Zn}$ & 9.45 \\
& $\mathrm{Se}$ & 55.41 & & $\mathrm{Se}$ & 53.49 \\
\hline
\end{tabular}


Table S4. The surface component percent of $\mathrm{Cu}, \mathrm{Zn}$ and $\mathrm{Sn}$ for uniform $\mathrm{Cu}$-poor and bottom $\mathrm{Cu}$-higher CZTSSe films derived from XPS.

\begin{tabular}{cccccc}
\hline sample & $\mathrm{Cu}(\%)$ & $\mathrm{Zn}(\%)$ & $\mathrm{Sn}(\%)$ & $\mathrm{Cu} /(\mathrm{Zn}+\mathrm{Sn})$ & $\mathrm{Zn} / \mathrm{Sn}$ \\
\hline Reference & 41.56 & 31.12 & 27.32 & 0.71 & 1.14 \\
Bottom Cu-higher & 42.94 & 31.02 & 26.04 & 0.75 & 1.19 \\
\hline
\end{tabular}

